ORIGINAL ARTICLE

\title{
Evaluation of Naked Eye Single Tube Red Cell Osmotic Fragility Test (NESTROFT) in Screening and Diagnosis of Beta Thalassaemia Trait in Pakistani Population
}

\author{
Rubina Ghani', Nazish Jaffar' ${ }^{2}$ Abdul Rehman², Kiran Abbas'2, Sayeda Fatima Ali', Ayesha Anum ' \\ 'Pathological and Molecular Laboratories, Musavvir Stem Cell Clinic, Karachi, ${ }^{2}$ Department of \\ Pathology, Sindh Medical College, Jinnah Sindh Medical University, Karachi, Pakistan.
}

\begin{abstract}
Background: Beta thalassaemia, an inherited disease that is a cause of continuous burden on the affected families and the society. The objective of the study was to evaluate the efficacy of Naked Eye Single Tube Red Cell Osmotic Fragility Test (NESTROFT) for the detection of beta thalassaemia trait when used for the screening in Pakistani population.

Methods: All participants requesting a complete blood count were included in the study. Informed consent was obtained. Naked Eye Single Tube Red Cell Osmotic Fragility Test was performed with freshly prepared $0.36 \%$ buffered saline. Turbidity in the tubes was an indication for individuals to be positive for beta thalassaemia trait. Hemoglobin electrophoresis was performed on all positive cases to confirm the sensitivity and the reliability of the screening test. Chi-Square test was used to test for any significant correlation between the different hematological parameters and other variables.
\end{abstract}

Results: A total of 812 patients were included in the study from January 2017 to June 2017. The mean age of participants was $35.5 \pm 13.6$ years. There were 351 (43.2\%) male and 461 (56.7\%) female participants. A $100 \%$ Naked Eye Single Tube Red Cell Osmotic Fragility Test sensitivity was obtained with 65 (8\%) positive cases having HbA2 levels of more than $3.2 \%$ indicating their true positivity whereas, all 747 (92\%) negative cases having $\mathrm{HbA} 2$ levels of less than $3.2 \%$ indicating their true negativity.

Conclusion: NESTROFT was found a highly sensitive, cost-effective, and a rapid screening test for the identification of carriers of beta thalassaemia trait in our population.

Keywords: Consanguineous Marriage; Population; Thalassaemia; Screening.

\section{Corresponding Author:}

Dr. Nazish Jaffar

Pathology Department,

Sindh Medical College,

Jinnah Sindh Medical University, Karachi.

Email: drnazishamin@gmail.com

https://doi.org/10.36283/PJMD10-1/002

\section{INTRODUCTION}

Beta Thalassaemia is a group of inherited blood disorders in which the body's ability to produce normal hemoglobin is impaired with reduction in capacity of red blood cells to carry oxygen'. Beta thalassaemia is more prevalent in Mediterranean regions, Indian subcontinent, the Middle East, and Southeast Asia'².

It has been estimated that about 5 to 9 thousand infants are born with beta thalassaemia every year, in Pakistan. However, no central registry is available in Pakistan to ascertain the actual number of cases of the disease per year ${ }^{3}$. Nevertheless, the carrier rate in Pakistan ranges between 5-8\%, meaning about 9.8 million people are carriers of beta thalassaemia trait in our population ${ }^{4}$. Following Sickle cell anemia, Beta thalassaemia is considered the second most common haemoglobinopathy, worldwide $^{5}$. Beta thalassaemia major is a severe disease and places a huge economic burden on the health 
care setup especially in developing countries like Pakistan and India'.

The early detection of asymptomatic carriers of thalassaemia (heterozygotes) makes it possible to provide genetic counseling, which may prevent a more severe homozygous condition in the offspring and its fatal outcome. In 2006, Saudi Arabia Health Ministry implemented a mandatory premarital screening of Thalassaemia trait in couples. Ahmad Al Suliman reported the beta thalassaemia trait incidence rate of $3.4 \%$ in his population. Parts of the world where blood disorders are highly prevalent, high-risk marriages should be prevented by implying premarital screening ${ }^{7}$.

Naked Eye Single Tube Red Cell Osmotic Fragility Test (NESTROFT) is a single tube qualitative osmotic fragility test based on the limit of hypo tonicity, which the red blood cells can withstand. In 2012, Chakrabarti et al. tested the validity of NESTROFT as a screening tool for beta thalassaemia trait. He reported NESTROFT to be $95 \%$ sensitive in subjects with at least one family member suffering from beta thalassaemia major while $85.71 \%$ sensitive in normal population ${ }^{6}$.

In 2007, Mamtani et al. reported her findings that supported the practice of NESTROFT use as a screening tool for beta thalassaemia trait in countries where there is a high prevalence of thalassaemia against minimal resources ${ }^{8}$. Another study from North India in 2013, reported a NESTROFT sensitivity of $100 \%$ and a specificity of $85.47 \%$ among 150 patients, indicating that NESTROFT is a useful screening tool that is both effective and affordable? ${ }^{9}$. The objective of this study was to evaluate the efficiency of Naked Eye Single Tube Red Cell Osmotic Fragility Test (NESTROFT) in determining beta thalassaemia trait in Pakistan population.

\section{METHODS}

A prospective, cross-sectional study was carried out at the Pathological and Molecular laboratories, Karachi, Pakistan from 1st January, 2017 to 30th June, 2017. All the patients (812) presenting to the laboratory and requesting a complete blood count (CBC) were enrolled in the study. The study participants belonged to different age groups and had a variable demographic profile. The ethical approval was obtained from the Institutional Review Board of the Molecular and Pathological Laboratories, Karachi, with IRB reference number of MSCC/ER$B / 2016 / 07$. Informed consent was taken from all patients prior to sample collection. Both genders that consented were included in the study.

The venous blood of $2.5 \mathrm{ml}$ was collected into a vacuum enabled tube containing Ethylenediaminetetraacetic acid (EDTA) anticoagulant (1.5 \pm $0.25 \mathrm{mg} / \mathrm{ml}$ ). Within two hours of sample collection, NESTROFT and Complete blood counts (CBC) were performed. CBC was done on Automated Hematology Analyzer (BC-3000 Plus-Mindray). NESTROFT was performed using freshly prepared $0.36 \%$ buffered saline. In addition, $5 \mathrm{ml}$ sterile test tubes were used each containing $4 \mathrm{ml}$ of $0.36 \%$ buffered saline. 50 $\mathrm{ul}$ sample blood was added in each tube. The tubes were left undisturbed at room temperature for at least 30 minutes. The turbidity in the tubes was observed in the presence of a tube light placed behind them. Turbidity in the tubes indicated that the individual was positive for beta thalassaemia trait.

Hemoglobin electrophoresis was performed on all NESTROFT positive cases to confirm the sensitivity and the reliability of the screening test NESTROFT. The formulae used to calculate sensitivity for the NESTROFT is shown below. Sensitivity = True Positive / True Positive + False Negative $\times 100$. Statistical Package for Social Sciences (SPSS v. 25) was used to perform data analysis. Measures of central tendency (mean and median) as well as standard deviation, SD; range: minimum - maximum was calculated.

\section{RESULTS}

A total of 812 patients were enrolled in the study between January 1, 2017 and June 30, 2017. The mean age $\pm S D$ of participants were $35.5 \pm 13.6$ years. There were 351 (43.2\%) male and 461 (56.7\%) female participants. High grade fever and symptoms of anemia were presenting complaints in majority of the patients. The demographic data and presenting complaints of patients are depicted in Table 1. The mean value for red blood indices, white blood cell, and platelet count was observed (Table 1). NESTROFT done in test tubes showed Positive and negative results (Figure 1). 
Table 1: Laboratory diagnosis of red blood cell indices, demographic and clinical profile of participants of the study.

\begin{tabular}{|c|c|c|c|}
\hline Complete Blood Count & $($ Mean $\pm S D)$ & Demographics & Mean \pm SD \\
\hline Hemoglobin $(\mathrm{Hb})$ & $12.57 \pm 2.10 \mathrm{mg} / \mathrm{dl}$ & Age & $35.5 \pm 13.6$ years \\
\hline Red Blood Cell (RBC) & $\begin{array}{c}4.86 \pm 0.78 \times 10^{12} \\
\text { cells per liter }\end{array}$ & \multicolumn{2}{|c|}{ Gender $\mathbf{n}(\%)$} \\
\hline Hematocrit (Hct) & $42.60 \pm 6.59 \%$ & Male & $351(43.2)$ \\
\hline Mean Corpuscular Volume (MCV) & $88.42 \pm 11.76 \mathrm{FL}$ & Female & $461(56.7)$ \\
\hline Mean cell hemoglobin $(\mathrm{MCH})$ & $26.06 \pm 3.74 \mathrm{pg}$ & \multicolumn{2}{|c|}{ Signs and Symptoms $n(\%)$} \\
\hline $\begin{array}{l}\text { Mean cell hemoglobin } \\
\text { concentration (MCHC) }\end{array}$ & $29.44 \pm 1.98 \%$ & Fever & $617(75.9)$ \\
\hline White Blood Cell (WBC) & $\begin{array}{c}9194.70 \pm 6216.74 \\
\text { cells } / \mathrm{mm}^{3}\end{array}$ & Lethargy & $523(64.4)$ \\
\hline Platelet count & $\begin{array}{c}271,461.82 \pm \\
104194.02 \text { cells } / \mathrm{mm}^{3}\end{array}$ & Shortness of breath & $400(49.2)$ \\
\hline Positive cases of anemia $n(\%)$ & $293(36.1 \%)$ & Pale skin & $253(31.2)$ \\
\hline
\end{tabular}

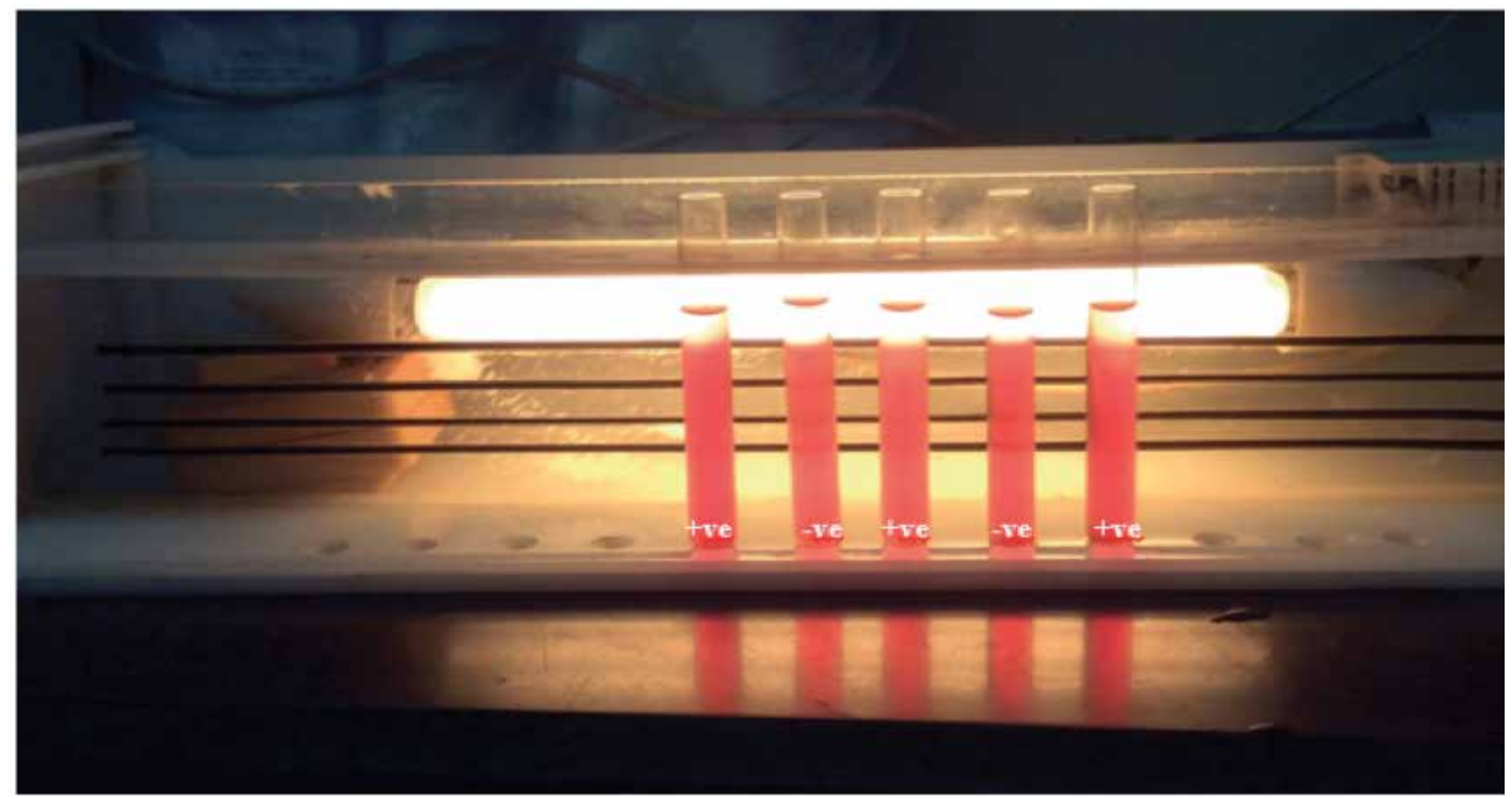

Figure 1: Demonstration of Naked Eye Single-Tube Red Cell Osmotic Fragility Test (NESTROFT) performed during the study.

In the present study, 293 (36.1\%) participants were anemic, out of these 205 (69.9\%) were female and only $88(29.1 \%)$ were male participants $(p=0.000)$. The mean \pm SD hemoglobin level in anemic patients was $10.89 \pm 1.92 \mathrm{mg} / \mathrm{dl}$ with a range of 4.90 to 13.40 $\mathrm{mg} / \mathrm{dl}$. We reported that $65(8 \%)$ participants in our study screened positive with NESTROFT for beta thalassaemia trait.

In our study, $\mathrm{Hb}$ electrophoresis for HbA2 levels was measured for all participants to detect the true positive and true negative cases. A $100 \%$ NESTROFT 
sensitivity was obtained with all 65 (8\%) positive cases having HbA2 levels of more than $3.2 \%$ indicating their true positivity whereas, all 747 (92\%) negative cases having $\mathrm{HbA} 2$ levels of less than $3.2 \%$ indicating their true negativity (Figure 2).

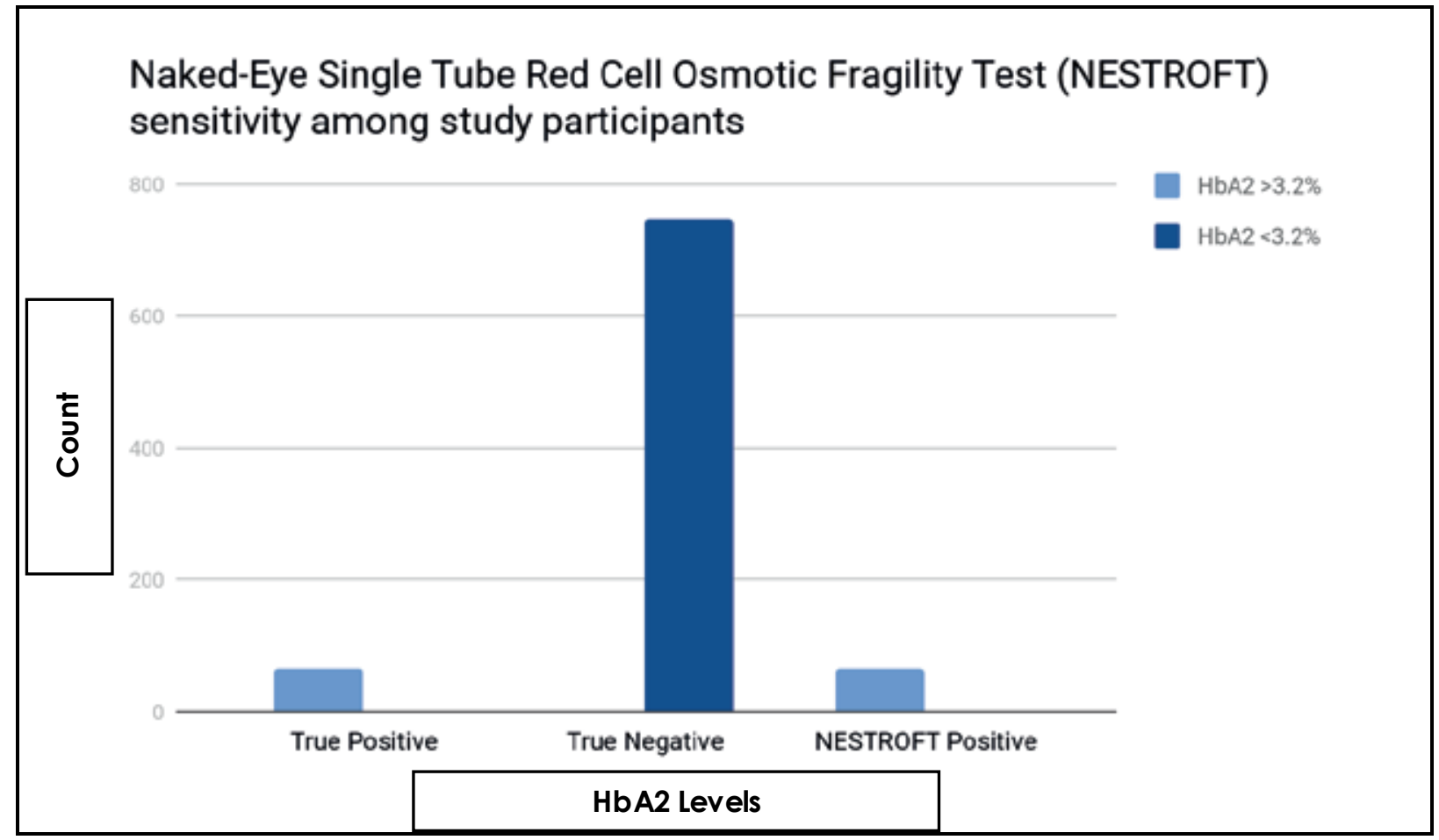

Figure 2: Results of $\mathrm{HbA} 2$ levels, indicating the true positive and negative cases.

In the present study, the patients who were screened positive for the beta thalassaemia trait with NESTROFT had reportedly a higher value of red blood cell count (RBC) and lower value of mean corpuscular volume (MCV) and mean cell hemoglobin $(\mathrm{MCH})$ as compared with the subjects who were negative for the trait (Figure 3).

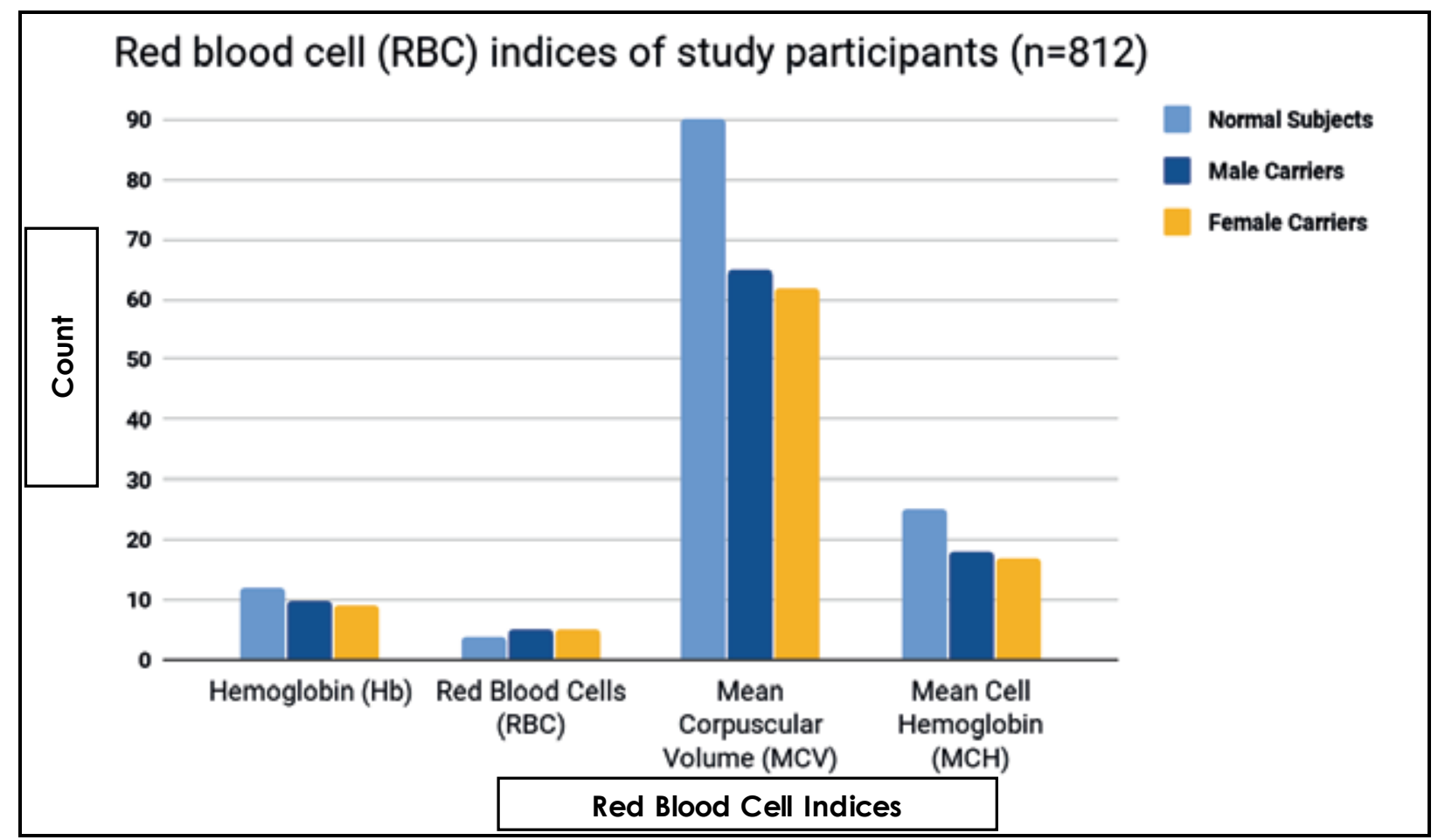

Figure 3: Red Blood Cell Indices (Hb, RBC, MCV, MCH) of carrier subjects as compared to non-carrier subjects in our study population. 


\section{DISCUSSION}

In the current study, we reported $8 \%$ positivity of beta thalassaemia trait in participants using NESTROFT. Furthermore, Hemoglobin electrophoresis confirmed $100 \%$ sensitivity of this test observed in all $8 \%$ of the samples. Thalassaemia is a hereditary blood disorder that is common in the Mediterranean and South Asian countries including Pakistan. The estimated carrier rate in Pakistan is between $5-7 \%$ with over 5,000 new patients being diagnosed with this disease each year ${ }^{10,11}$. Thalassaemia is not only responsible for huge mortality and morbidity but also causes considerable socioeconomic burden on the affected families and the government.

Many different screening techniques are available for the detection and confirmation of Thalassaemia but most of these tests are expensive hence, not all patients are able to afford them. Besides, Pakistan is a resource-poor region and not every diagnostic laboratory has the advanced equipment to screen and detect even the most prevalent of diseases ${ }^{12}$.

Therefore, it is crucial to evaluate the efficacy of various screening methods, which are both accessible and inexpensive. Patients with deranged red blood indices concomitant with symptoms of anemia must be screened thoroughly for beta thalassaemia trait. Presence and relative amounts of abnormal forms of hemoglobin is a preliminary diagnosis of a hemoglobin disorder. Elevated hemoglobin A2 (HbA2) of more than $3.5 \%$ as detected on High Performance Liquid Chromatography (HPLC) or cellulose acetate electrophoresis $(\mathrm{CAE})$ is the definitive diagnosis for beta thalassaemia trait ${ }^{12,13}$. These tests are accurate but costly and labor intensive. Keeping these problems in mind, we sought to evaluate the efficacy of NESTROFT, an inexpensive and a simple technique to screen the carriers of Beta Thalassaemia trait in our population $^{14}$.

NESTROFT was introduced in the 1990's and since then many studies have tried to evaluate its efficacy in diagnosing beta thalassaemia trait for screening purpose. NESTROFT is considered to be a very simple and cheap tool to detect carrier state in normal population. However, this test is dependent upon visual interpretation. Gorakshaker et al. determined the inter-observer variability while recording of NESTROFT results by three individuals on blood samples of 380 participants $^{15}$. They observed that there was little variation in recording the negative results while greater variation in positive or doubtful cases. They concluded that NESTROFT should be considered as the investigation of choice for initial screening of Beta thalassaemia trait in Indian population.
In the present study, NESTROFT was reported to be $100 \%$ sensitive as confirmed with $\mathrm{HbA} 2$ value of more than 3.2 indicating the true positivity of beta thalassaemia trait carriers. Since 1991, many studies were conducted to determine the efficacy of NESTROFT as a screening tool for beta thalassaemia trait among normal population ${ }^{6-20}$. These studies reported that $96-100 \%$ of heterozygotes with beta thalassaemia trait could be detected with NESTROFT. Their findings were in accordance with this study. Our study also, supported the claim that NESTROFT is an effortless, economical, and easy to perform technique that could be utilized for screening at a large scale.

A similar study carried out in by sumera et al. reported NESTROFT to be $93 \%$ sensitive and $88 \%$ specific. An Indian study showed $100 \%$ and $92.9 \%$ sensitivity and specificity respectively, claiming that NESTROFT was the most effective, inexpensive, and accurate test for screening for beta thalassaemia trait 16,17 .

A study conducted at Jinnah University for women, Karachi evaluated the diagnostic significance of NESTROFT and red blood indices in screening beta thalassaemia minor in subjects. According to the study, compared with the control group, all 100 participants in the carrier group showed a positive NESTROFT test with concomitant low values of $\mathrm{MCH}$ and MCV making NESTROFT to be a rapid and a reliable method for the detection of thalassaemia trait among our population ${ }^{18}$. Pakistan is one of the highly prevalent countries suffering from inherited haemoglobinopathies, which poses a huge economic burden on the country ${ }^{2,19}$.

A recent study reported that the consanguineous population was significantly associated with an increased prevalence of diseases such as diabetes mellitus, haemoglobinopathy, and mental illness$\mathrm{es}^{20-22}$. It is essential to screen for beta thalassaemia trait carriers among Pakistani population because consanguineous marriages are practiced at an alarmingly high rate of $81 \%{ }^{23}$. Therefore, it is important to educate the public about the possible devastating outcomes of a consanguineous marriage and to prevent beta thalassaemia major by genetic counseling and mass screening for beta thalassaemia trait. It was found that with the help of genetic counseling, beta thalassaemia major in infants could be reduced by as much as $90 \%{ }^{12}$. In contrast to mass screening by NESTROFT, Baig et al claimed that it is better to do cascade testing of large families with consanguinity practices instead of mass screening in Pakistan, which has limited health resources ${ }^{23}$.

A cross sectional study conducted in 2015 in Lahore 
where 25 families were screened for beta thalassaemia trait negated our findings. NESTROFT was only $55 \%$ sensitive and $64 \%$ specific whereas, the Positive Predictive Value was $46 \%$ and Negative Predictive Value was $64 \%$. Similarly, about $66.7 \%$ detection of beta thalassaemia trait was reported in a study from Myanmar. However, both these studies are insufficient to disregard a seemingly good screening tool, as NESTROFT is highly dependent on the visual interpretation and the concentration of buffered saline 24,25 . We believe that to consider NESTROFT as a reliable screening tool, studies with larger sample size would be required in future valuable screening tool for identification of carriers of beta thalassemia trait. All NESTROFT positive cases should be advised further workup to confirm their diagnosis. Genetic counseling should be offered to all carriers of beta thalassaemia trait in order to reduce the incidence of beta thalassemia major in Pakistan. We recommend that all families where consanguineous marriages are practiced NESTROFT should be advised to screen for haemoglobinopathy. We recommend studies on larger scale utilizing NESTROFT to establish its reliability as a screening method.

\section{CONCLUSION}

NESTROFT is a highly sensitive, cost-effective, and a rapid screening test for the identification of carriers of beta thalassaemia trait in our population. Such selective but extensive screening practice would eventually reduce the burden of thalassaemia major in Pakistan.

\section{ACKNOWLEDGEMENTS}

We are thankful to Pathological and Molecular Laboratories, Musavvir Stem Cell Clinic Karachi for providing us the diagnostic facilities.

\section{CONFLICT OF INTEREST}

The authors declare no conflict of interest.

\section{ETHICS APPROVAL}

Ethical approval was provided by Institutional Review Board of Pathological and Molecular Laboratories, Musavvir Stem Cell Clinic, Karachi, Pakistan (MSCC/ERB/2016/07).

\section{PATIENT CONSENT}

All the participants in the study gave written informed consent before data collection.

\section{AUTHORS' CONTRIBUTION}

RG had conceived the idea and done the laboratory testing; NJ did the manuscript writing. AR did statistics; KA did critical review and editing. SFA did literature review and AA performed the data collection.

\section{REFERENCES}

1. Origa R. $\beta$-Thalassemia. Genet Med. 2017;19(6):609-619. 2. Ferdousi A, Ahmad M, Sharma JD, Samad R, Ullah AZ. Role of naked eye single tube red cell osmotic fragility test (nestroft) in detecting beta-thalassaemia trait. J Bangladesh Coll Phys Surg. 2018;36(4):145-152.

3. Ansari SH, Shamsi TS, Ashraf $M$, Bohray M, Farzana T, Khan MT, et al. Molecular epidemiology of $\beta$-thalassemia in Pakistan: far reaching implications. Int J Mol Epidemiol Genet. 2011 ;2(4): 403-408.

4. Ali N, Moiz B, Bin Azhar W, Zaidi N, Memon R. Carrier detection for beta-thalassemia trait in general Pakistani population: a way forward. Hematol. 2012;17:4, 237-240.

5. Li CK. New trend in the epidemiology of thalassaemia. Best Pract Res Clin Obstet Gynaecol. 2017;39:16-26

6. Chakrabarti I, Sinha SK, Ghosh N, Goswami BK. Beta-thalassaemia carrier detection by NESTROFT: An answer in rural scenario? Iran J Pathol. 2012;7(1):19-26.

7. Al-Suliman A. Prevalence of $\beta$-thalassemia trait in premarital screening in Al-Hassa, Saudi Arabia. Ann Saudi Med. 2006;26(1):14-16.

8. Mamtani M, Das K, Jawahirani A, Rughwani V, Kulkarni $H$. Is NESTROFT sufficient for mass screening for $\beta$-thalassaemia trait? J Med Screen. 2007; 14(4): 169-173.

9. Piplani S, Manan R, Lalit M, Manjari M, Bhasin T, Bawa J. NESTROFT-a valuable, cost effective screening test for beta thalassaemia trait in north Indian Punjabi population. J Clin Diagn Res. 2013;7(12): 2784-2687.

10. Sajjad SF, Ahmad W, Hussain JSS, Asif M, Alam SE. Treatment of chronic hepatitis $C$ in thalassemia major patients. J Pak Med Assoc. 2017;67(6):926-928.

11. Khan MI, Khan HN, Usman M. Beta thalassemia trait; diagnostic importance of haematological indices in detecting beta thalassemia trait patients. Professional Med J. 2018; 25(4):545-550.

12. Hussain Z, Malik N, Chughtai AS. Diagnostic significance of red cell indices in beta-thalassemia trait. Biomedica. 2005;21 (2):129-131.

13. Stephens AD, Colah R, Fucharoen S, Hoyer J, Keren D, McFarlane A, International Council for Standardization in Haematology (ICSH), et al. ICSH recommendations for assessing automated high-performance liquid chromatography and capillary electrophoresis equipment for the quantitation of $\mathrm{HbA} 2$. Int $\mathrm{J} \mathrm{Lab}$ Hematol. 2015;37(5):577-582.

14. Colah RB. The use of NESTROFT for screening pregnant women for detection of $\beta$-thalassemia carriers. J Fetal Med. 2015;2(1):9-10.

15. Gorakshaker AC, Colah R, Nadkarni A, Desai S. Evaluation of the single tube osmotic fragility test in detection of B-thalassaemia trait. Natl Med J India. 
1990;3:171-173.

16. Sumera A, Ahmed S, Ali SA, Khanani R. Evaluation of NESTROFT as a marker of differentiation between $\beta$-thalassemia trait and iron deficiency anemia. Int J Collab Res Intern Med Public Health. 2012;4(8):1560-1566.

17. Safia R, Jairajpuri ZS, Khetrapal S, Hassan MJ, Gupta M, Jetley S. An analysis of NESTROFT and Red cell indices in evaluating antenatal mothers for beta thalassaemia trait. Bangladesh J Med Sci. 2018;17(3):411-416.

18. Afshan N, Hussain M. Diagnostic significance of $\mathrm{MCV}, \mathrm{MCH}$ AND NESTROFT in thalassemia minor individuals. J Biol Res Appl Sci. 2012;3(2):21-24.

19. Khan K, Zahoor S. Pattern of Hemoglobinopathies on HPLC among patients referred to selected centers in Peshawar, Pakistan. Rawal Med J. 2018:43(4):623-626.

20. Bener A, Mohammad RR. Global distribution of consanguinity and their impact on complex diseases: Genetic disorders from an endogamous population. Egypt J Med Hum Genet. 2017;18(4):315-320.
21. Bhinder MA, Sadia H, Mahmood N, Qasim M, Hussain Z, Rashid MM, et al. Consanguinity: A blessing or menace at population level? Ann Hum Genet. 2019;83(4):214-219.

22. Romahane L, Mezzi N, Hamdi Y, El-Kamah G, Barakat A, Abdelhak S. Consanguinity and inbreeding in health and disease in north African populations. Annu Rev Genomics Hum Genet. 2019;20:155-179.

23. Baig SM, Din MA, Hassan $H$, Azhar A, Baig JM, Aslam $M$, et al. Prevention of $\beta$-thalassemia in a large Pakistani family through cascade testing. Public Health Genomics. 2008; 11 (1):68-70.

24. Akhter MA, Nayyar U, Majeed T, Dar UF. Nestroft validity for screening of extended families of thalassaemia patients. J Fatima Jinnah Med Univ. 2015:9(1):40-43

25. Aung KM, Lwin AA, Naw $H$, Mon NC, Soe $H O$, Oung MT, et al. Detection of common beta globin gene mutations on heterozygous beta thalassaemia including hemoglobin E among high school students' population. Int J Comput Eng Res Trends. 2020: 7(1):1-7. 